\title{
A empresa como sede do conhecimento
}

\author{
Denise T. Lisboa Bassani, Esp. \\ Universidade Federal Fluminense - UFF \\ Sonia Nikitiuk, Dr. Sc. \\ Universidade Federal Fluminense - UFF \\ Osvaldo Quelhas, Dr. Sc. \\ Mestrado Profissional em Sistemas de Gestão - UFF
}

\begin{abstract}
Resumo
Este artigo trata de um estudo de caso em que se procura evidenciar a importância do conhecimento para consecução da qualidade no ambiente organizacional. Os referenciais de análise são os critérios do Prêmio Nacional de Qualidade (1999) e observam a prática de treinamento realizada em uma organização de prestação de serviços de advocacia, especializada em Direito sobre a Propriedade Industrial.

A abordagem sobre a Lei de Propriedade Industrial nos cursos de Direito nas universidades brasileiras é ainda insuficiente para a atuação imediata de profissionais neste campo. O conhecimento extenso e profundo sobre esta área particular é usualmente adquirido nas empresas de advocacia especializadas neste campo. Devido à ausência de uma metodologia de treinamento e desenvolvimento de formação profissional, no caso focalizado, um determinado setor desta empresa utilizou a gestão do conhecimento como ferramenta para a melhoria da qualidade de seus serviços.

A organização e os funcionários foram beneficiados pela iniciativa, mas vários obstáculos impediram a sua continuidade. 0 trabalho presente discorre sobre a experiência da gestão sobre o conhecimento ocorrida neste caso, assim como registra as conseqüências e oportunidades para mudança.
\end{abstract}

\section{Palavras-chave}

Qualidade, gestão de pessoas e gestão do conhecimento.

\section{The company as the headquarters of knowledge}

\begin{abstract}
This article refers to a case study where there is a pursuit to evidence the importance of the knowledge for the quality achievement in the organizational environment. The analysis referential is the Prêmio Nacional de Qualidade (1999) criteria and it refers to the training practice in a law firm specialized in Intellectual Property.

The approach on Industrial Property Law in Law courses into Brazilian Universities appears to be still insufficient for the immediate practice by professionals in this field. The thorough and extensive knowledge over this particular area have usually been acquired into private Law offices specialized in this field. Due to the absence of a training and professional background development methodology in the referred case, one of its cells made use of the knowledge management as a tool for improving quality in rendering its services.

The organization and the employees got the benefits from the initiative, but there were many obstacles that prevented the permanence of such program. This study relates the experience about the knowledge management that occurred in this organization, as well its consequences and opportunities for a change.
\end{abstract}

\section{Key words}

Quality, people management and knowledge management. 


\section{INTRODUĈ̣̃O}

"Talvez o resultado mais valioso de toda a educação seja a capacidade de levá-lo a fazer o que deve ser feito, quando deve ser feito, queira você ou não; esta é a primeira lição a aprender; e... talvez o último ensinamento que se aprende em sua plenitude - a grande finalidade da vida não é o conhecimento, mas a ação."

(HUXLEY apud STEWART, 2002)

Os investimentos na formação de competências e de valoração do capital humanos devem ser tão prioritários quanto os investimentos em capital físico. Ao examinar a recuperação dos países europeus e do Japão após a II Guerra Mundial, em contraste com a estagnação econômica de muitos países subdesenvolvidos, Drucker (1999) observou o caminho para esta transformação de base na cultura organizacional. Segundo ele, o grande desafio das organizações é identificar e promover a mudança contínua, consistindo em rever criticamente o conhecimento antigo e criar o novo através dos seguintes aspectos:

- melhoria contínua de todas as atividades (kaizen);

- desenvolvimento de novas aplicações a partir de seus próprios recursos;

- inovação contínua como um processo organizado.

Esta afirmação de Drucker (1999), se feita algum tempo atrás, certamente conduziria a um maior investimento sobre os recursos tecnológicos. Entretanto, passadas algumas décadas da difusão dos recursos da informática, o foco sobre a formação do capital humano ficou ainda mais evidente nos dias de hoje.

Os trabalhadores de uma organização formam a sua estrutura. Portanto, o desafio das empresas de hoje é formar e integrar uma boa equipe de trabalho com conhecimento, capacidade e habilidades específicas para os postos de trabalho, para cumprirem as tarefas exigidas e para pensarem estrategicamente sobre os destinos da organização.

E o conhecimento é a própria razão de ser da organização. O valor global do conhecimento de uma empresa pode ser verificado quando ela é comprada por um valor superior ao seu valor contábil. Esta diferença consiste normalmente em ativos intelectuais: marcas, patentes, profissionais especializados, criação de novos produtos, mapa de preferências de clientes, etc.

$\mathrm{O}$ valor do conhecimento não é nenhuma novidade. A novidade é apontá-lo como um recurso carente de ser gerenciado e utilizado no âmbito organizacional. É consi- derá-lo como componente do planejamento estratégico e como propulsor de dinâmicas que facilitarão a formação de equipes e o compartilhamento da visão na empresa.

Assim sendo, torna-se necessário formular uma estratégia com base na gestão de pessoas através de planos e estratégias, concentrando-se no desenvolvimento de capacidades e competências essenciais em longo prazo, que serão encarregadas de criar o diferencial competitivo. Gramignia (2001) apud Mamani (2002) ressalta a importância da área de recursos humanos para atrair, desenvolver e reter pessoas talentosas, uma vez que o domínio de determinadas competências faz com que profissionais e organizações façam diferença no mercado. Na Figura 1 a raiz representa o conjunto de valores; o tronco representa o conhecimento; e a copa representa as habilidades. Didaticamente, tal representação conduz ao entendimento da construção do conhecimento como base da competência do indivíduo e da organização:

\section{$\Lambda$ vantagem do conhecimento é que está sempre evoluindo e gera retornos crescentes.}

Etimologicamente, aprender vem do latim apprehendere, que significa apoderar-se, prender, dominar. Então, aprendizagem significa aquisição de conhecimento ou habilidade. Ela pode ser definida como um processo de integração e adaptação do ser ao ambiente em que vive, implicando, pois, em mudança de comportamento; enquanto educação vem de ex ducere, que significa conduzir para fora. Este trabalho procura refletir sobre o significado da aprendizagem do indivíduo em ambiente organizacional, enfatizando o valor que pode ser agregado através da mudança de atitude de toda a empresa em relação à construção de programas de treinamento específicos aos indivíduos recém-admitidos, assim como os estímulos para a expansão do conhecimento através de cursos internos ou externos aos funcionários veteranos mais talentosos. Trata-se de conduzir, para mentes ávidas, o ferramental adequado para que o caos organizacional seja apreendido e transformado em ambiente harmônico de produção coletiva, estimulando e incentivando a criação de novos produtos e a melhoria dos produtos existentes, conseguindo para a organização a vantagem competitiva e uma valorização humana por excelência.

Levando em consideração o arrazoado acima, toma-se por estudo uma experiência ocorrida num determinado setor de uma empresa prestadora de serviços: um grande 
escritório de advocacia especializado em Propriedade Industrial. O caso estudado versa sobre os benefícios oriundos da gestão de conhecimento gerados para a empresa e para as pessoas, assim como as consequiências e oportunidades nascidas deste fato.

\section{O PROBLEMA}

Os autores perceberam a carência na bibliografia existente, inclusive no que diz respeito a estudos de caso, quanto à oportunidade de registrar uma aplicação dos conceitos de gestão do conhecimento para a melhoria contínua de uma organização e, concomitantemente, a qualificação profissional e a melhoria de vida dos indivíduos contemplados por ela. Quinn et al. (1998) tece o apropriado comentário:

"A capacidade de gerenciar o intelecto humano - e de convertê-lo em produtos e serviços úteis - está rapidamente se tornando a habilidade executiva crítica do momento. Como resultado, tem havido uma enxurrada de interesses no capital intelectual, na criatividade, na inovação e na organização que aprende, mas surpreendentemente, pouca atenção tem sido dada ao gerenciamento do intelecto profissional."

\section{METODOLOGIA DE PESQUISA}

A metodologia de pesquisa utilizada neste estudo é baseada em uma perspectiva exploratória, constituindo-se de utilização de pesquisa bibliográfica, coleta de dados, observação e análise de verbalizações de participantes na organização estudada, orientando os dados coletados para a convergência de conclusões e proposições.

\section{FUNDAMENTAC̣̃̃O TEÓRICA}

\section{Definição de Conhecimento}

Para melhor entendimento, distingue-se o conhecimento nas seguintes etapas, em abordagem no âmbito organizacional, inspiradas em modelo apresentado por Davenport e Prusak (1999):

1 Dados: conjuntos de fatos distintos e objetivos, relativos a eventos. Num contexto organizacional, são registros de movimentações efetuadas disponíveis para ser consultados. Normalmente são armazenados em sistemas e devem ter as seguintes qualidades: precisão, disponibilidade, clareza e atualidade. Os dados não exibem por si sós significado: são apenas descritivos de ações passadas. Demandam

Figura 1: Desdobramento das competências.

\section{COMPETÊ N CIAS}

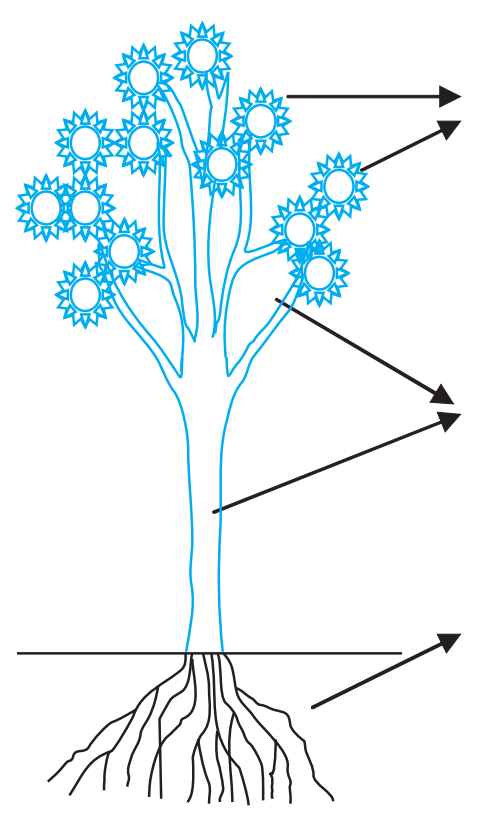

HABILIDADES

"Agir com talento,capacidade e técnica, obtendo resultados positivos: é o que chamamos de 'habilidade'.

"São comportamentos laborais automatizados pela prática e a experiência na execução de alguma tarefa específica."

\section{CONHECIMENTO}

Trata-se do conjunto de informações que a pessoa armazena, resultado da educação formal e da capacitação. 
interpretação, análise especulativa e julgamento. Não fornecem base para tomada de ação e sua multiplicidade pode confundir ao invés de esclarecer ou mapear uma situação; entretanto, constituem-se como matéria-prima para qualquer exame para se conseguir uma fotografia precisa sobre o procedimento que se quer alterar ou criar e, melhor, para a criação da informação.

2o Informação: documento ou comunicação audível ou visível. É a transmissão de dados de um emitente para o receptor. É plena de significado, relevância e propósito fornecidos pelo emitente, que intencionalmente dá forma aos dados para atingir o objetivo do conhecimento pelo receptor. A informação tem como objetivo alterar a visão do receptor sobre a questão que se apresenta. Entretanto, cabe ao julgamento do receptor considerar se a informação é relevante ou não. Os dados são transformados em informação quando são agregados valores.

Uma análise mais aguda permite fazer a diferença entre a informação e o meio que a viabiliza. A Internet e a Intranet viabilizam e disponibilizam a informação, mas o que é realmente importante é a informação que é divulgada. Os meios tecnológicos apenas facilitam e agilizam com precisão a dispersão da informação, mas não são por si sós os responsáveis por se obter a melhor informação nem mesmo a garantia de que esta informação irá chegar às pessoas certas.

3o Conhecimento: O conhecimento está na cabeça das pessoas. É mistura de vários elementos, intuição, insights, faz parte da complexidade e imprevisibilidade humanas. Poder-se-ia definir, grosso modo, o conhecimento como uma mistura fluida de experiência condensada, valores, crenças, informação contextual e insight experimentado, a qual proporciona uma estrutura para a avaliação e incorporação de novas experiências e informações. Segundo Stewart (2002), “...conhecimento não é soma, é agregação, interação e acumulação [...] envolve expertise. Para alcançá-lo é preciso tempo. O conhecimento dura mais do que a informação - e por vezes é eterno. Ter conhecimento, dominar um assunto, é algo diferente e maior do que saber de um fato ou possuir muitas informações a respeito de alguma coisa".

\section{Gestão do Conhecimento}

Segundo Stewart (2002), no âmbito de uma organização, "gestão do conhecimento é identificar o que se sabe, captar e organizar esse conhecimento e utilizá-lo de modo a gerar retornos".

Oliveira Júnior (2001) observa que a função central da empresa é administrar este ativo intangível de forma a otimizar o desempenho organizacional. "O que vai determinar o sucesso da empresa é a sua eficiência nesse processo de transformação de conhecimento existente no plano das idéias para o conhecimento aplicado no plano das ações, em comparação com a eficiência de outras empresas." (Kogut e Zander, 1993 apud Oliveira Júnior, 2001).

\section{Capital Intelectual}

Capital Intelectual, segundo Stewart (2002)

"...é o conhecimento que transforma as matérias-primas e as torna mais valiosas"[....] "Tornou-se comum dizer que o capital intelectual de uma empresa é a soma de seu capital humano (talento), capital estrutural (propriedade intelectual, metodologias, software, documentos e outros artefatos de conhecimento), e capital em clientes (relacionamentos com clientes)"

\section{A transformação do estado do conhecimento na organização}

Segundo Oliveira Júnior (2001), quando se fomenta o processo de aprendizagem identificando mecanismos e ferramentas de gestão que facilitem, disseminem e permitam à empresa possuir um maior controle sobre o processo, concomitantemente estão-se determinando as formas pelas quais o novo conhecimento vai ser criado - o conhecimento existente vai ser alterado - e como os fluxos de conhecimento vão ser transferidos internamente e também através dos limites da empresa.

\section{trabalhador que relata o seu desconhecimento sobre alguma prática está sinalizando o seu desejo em aprendê-la.}

Os níveis de aprendizagem organizacional foram descritos com precisão por Argyris e Schön $(1978,1996)$ apud Oliveira Júnior. (2001).

- A aprendizagem em circuito simples (single loop learning), que ocorre após a detecção de erros, sem questionar as políticas subjacentes às ações que geraram os erros;

- A aprendizagem em circuito duplo (double loop learning), que envolve o questionamento de valores, crenças e, conseqüentemente, das políticas decorrentes.

A Figura 2 representa o esquema sintetizando o movimento dos circuitos simples e duplo de aprendizagem.

Argyris (1992) apud Oliveira Júnior (2001) afirmou que para que os membros da organização pudessem desenvolver sua capacidade de produzir circuitos duplos, seria ne- 
Figura 2: Circuitos simples e duplo de aprendizagem.

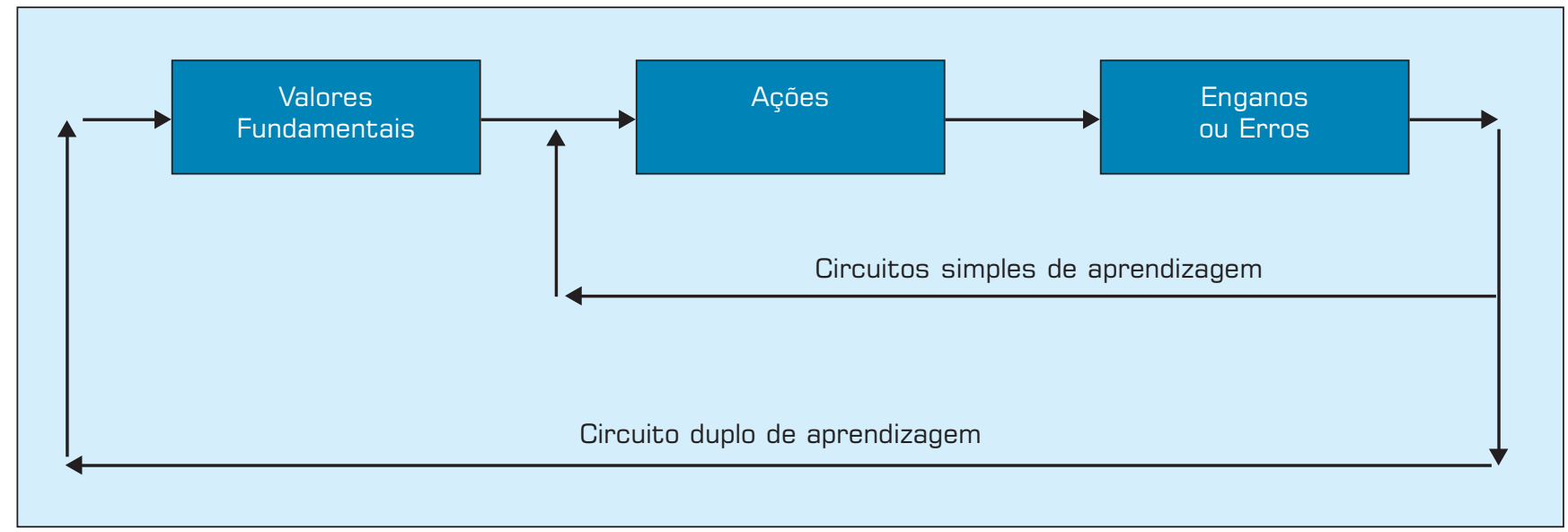

Fonte: Argyris, C. (1992) Enfrentando Defesas Empresariais: Facilitando o Aprendizado organizacional. Rio de Janeiro, Campus, pp. 112, apud Oliveira Jr. (2002).

cessário desenvolver uma cultura que premiasse ações dessa natureza. Fleury e Fleury (1995) apud Oliveira Júnior (2001), no entanto, afirmaram que o desenvolvimento de uma cultura organizacional de aprendizagem é dificultado devido à tendência natural, na maior parte das empresas, de uma preservação dos padrões culturais e de resistência à mudança, que propiciam o surgimento de normas que atuam como um impeditivo da adoção de práticas de gestão orientadas para uma aprendizagem mais eficiente e duradoura.

\section{Gestão de Pessoas}

O presente estudo privilegia com amplitude o papel sugerido ao setor de Recursos Humanos nas organizações com o termo Gestão de Pessoas, procurando apontar a importância desta estrutura na gestão do conhecimento, trazendo não só a vantagem competitiva para uma organização como promovendo vidas humanas à melhoria constante de trabalho e propondo novas oportunidades de desempenho intelectual.

Mamani (2002) referencia os objetivos da Gestão de Pessoas para contribuir para a eficiência organizacional através dos seguintes meios:

1) Ajudar a organização a alcançar seus objetivos e a realizar sua missão;

2) Proporcionar competitividade à organização;

3) Proporcionar organização aos empregados bem treinados, bem motivados;

4) Promover a auto-atualização e aumentar a satisfação dos empregados no trabalho;

5) Desenvolver e manter qualidade de vida no trabalho;

6) Administrar a mudança;

7) Manter políticas éticas e de comportamento socialmente responsável.

A moderna Gestão de Pessoas consiste em várias ativida- des, que podem ser resumidas em seis processos básicos, apresentados esquematizados na Figura 3.

\section{FOTOGRAFANDO UMA EMPRESA PRESTADORA DE SERVICQO — UM ESTUDO DE CASO}

A Gestão pela Qualidade Total aplicada a empresas prestadoras de serviços é de complexo gerenciamento, uma vez que os conceitos que retratam a excelência do serviço não são quantificáveis. Portanto, a qualidade do serviço é monitorada a partir de índices gerais, muitos associados aos resultados finais do negócio, tais como o número de clientes atendidos, os custos da prestação de serviços e as receitas geradas. Acrescentam-se aí os índices de desempenho dos setores, diferenciados pela natureza dos serviços internos, levando em consideração o tempo mínimo para a execução e a qualidade intrínseca dos mesmos. A satisfação dos clientes, quando medida, baseia-se na consecução de novos clientes e a não-satisfação, na perda sumária destes ou, mais atenuadamente, em suas manifestações de desagrado. $\mathrm{O}$ estudo de caso apontado por este trabalho considera o desenvolvimento e fortalecimento do conhecimento como fator de qualidade no trabalho e também como fator de desenvolvimento pessoal e social dos trabalhadores.

O caso escolhido para ilustrar o presente trabalho focaliza uma experiência ocorrida no Setor de Controle de uma empresa de Agentes de Propriedade Industrial. Tal setor é considerado como aquele cuja atuação é considerada como a alavanca principal para o funcionamento das rotinas de toda a empresa.

O Direito sobre a Propriedade Industrial é um ramo da advocacia que versa sobre a consecução, manutenção e defesa do privilégio e contratos de licenciamento das Marcas e Patentes. Ambas são frutos de direitos concedidos 
através de processo específico administrado pelo Instituto Nacional de Propriedade Industrial (INPI).

Alguns profissionais são inicialmente mais qualificados para cumprir estes serviços: aqueles originários dos cursos regulamentares de Direito, onde é ministrado o ensino básico sobre a Lei de Propriedade Industrial. Para transitar com maior conforto nesta área tão específica, tanto os advogados como outros interessados, com formação universitária ou não, contam com alguns cursos preparatórios ministrados pela associação nacional dos profissionais do gênero e, mais efetivamente, com a prática diária nos escritórios de Agentes de Propriedade Industrial.

$\mathrm{O}$ acompanhamento dos processos de Marcas e $\mathrm{Pa}$ tentes e a manutenção adequada destas após a concessão dos registros, exige uma estrutura bem equipada de recursos informatizados e mão-de-obra especializada no conhecimento profundo da Lei de Propriedade Industrial (LPI) para acompanhar e manter o funcionamento de dezenas de procedimentos administrativos, distribuídos pelos diversos setores de um escritório especializado neste ramo.

\section{Características da organização estudada}

A empresa onde se desenvolveu a ação escolhida para este estudo existe há mais de 40 anos no Brasil. À época do desenrolar da experiência ora apresentada, a empresa pos- suía aproximadamente 120 funcionários em sua folha de pagamento.

A liderança de maior expressividade dentro da empresa era exercida primordialmente pelo seu presidente, advogado sócio-proprietário e por outros componentes de sua família, igualmente advogados especializados na área de Propriedade Industrial. Outros líderes existiam, os sócios minoritários, responsáveis pelas Diretorias. Demais lideranças eram exercidas por gerentes que apresentavam comprometimento com a visão do presidente da empresa.

O organograma da empresa, para melhor compreensão de sua disposição funcional, é apresentado na Figura 4.

O recrutamento dos funcionários obedecia a critérios obtidos da necessidade de formar grupos definidos pela natureza das ações necessárias às marcas e patentes: advogados, engenheiros e estagiários de direito e de engenharia, que deviam estar aptos à comunicação fluente verbal e escrita em inglês. Outra camada de funcionários era composta por assessores administrativos, também chamados de paralegals (expressão tomada emprestada ao idioma inglês que significa pessoas que, com treinamento adequado, podem assistir a advogados), que deviam apresentar igual fluência em inglês. Dos demais funcionários necessários para dar o suporte operacional aos profissionais acima descritos, era exigido somente o segundo grau completo. Ou seja, não se exigia nenhum conhecimento da Lei de

Figura 3: Os processos da Gestão de Pessoas.

GESTÃO DE PESSOAS

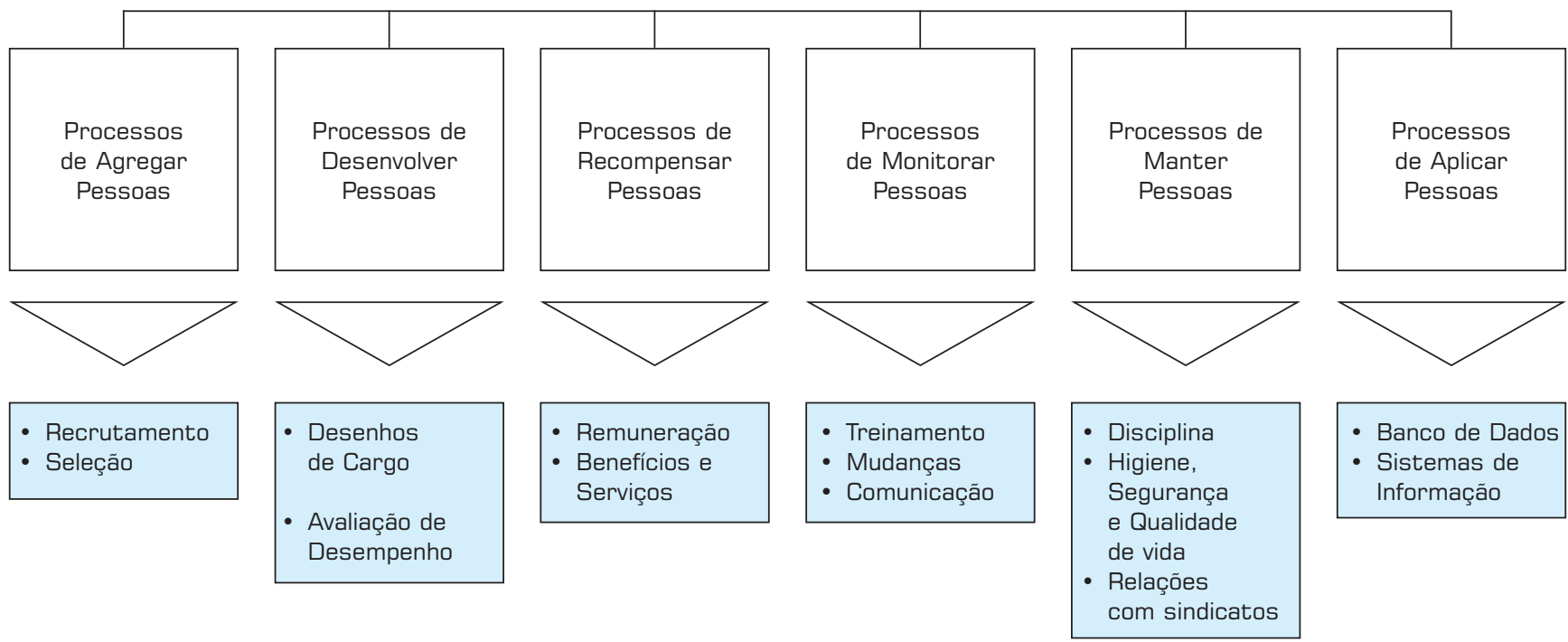

Fonte: Chiavenato, apud Mamani, 2002. 
Propriedade Industrial para a admissão de funcionários, confiando-se mais no aprendizado a partir da prática diária. À parte desta organização estratificada, outros profissionais desempenhavam seus ofícios, tais como bibliotecária, contabilistas e secretárias.

O treinamento dos funcionários obedecia a critérios diferenciados pelos papéis a serem exercidos pelos advogados, engenheiros, técnicos/tradutores juniores. A formação profissional a ser dada a esses grupos de funcionários era posta a cargo de profissionais seniores escolhidos por suas notórias habilidades como educadores. Os profissionais juniores contavam também com o curso da Associação citada acima, que é ministrado sazonalmente.

Quanto aos demais funcionários em funções e/ou setores de apoio, os já citados paralegals, formavam dois grupos distintos: o que tinha conhecimento do idioma inglês e o que não tinha. Portanto o primeiro grupo tinha a habilidade em entender, apreciar e travar comunicação direta com o cliente. Ao segundo grupo eram delegadas tarefas operacionais.
Quanto aos clientes, a maior parte deles era composta por organizações de renome internacional, produtoras de bens e prestadoras de serviços, cujo objetivo era obter, através de processo específico administrado pelo INPI, o pleno direito sobre o privilégio de usarem e explorarem com exclusividade suas marcas e patentes neste país. A troca de comunicação com estes clientes se produzia preferencialmente por escrito e, via de regra, em inglês. Como estratégia para melhor atendimento aos clientes, era necessário o conhecimento e a utilização perfeita da Lei de Propriedade Industrial para a correta interpretação dos projetos solicitados pelos clientes e conseqüentes aconselhamentos diante do comportamento do INPI face aos citados projetos. Como critério de excelência do atendimento ao cliente, era exigida a todos os funcionários agilidade nas respostas, tanto às questões trazidas pelos clientes quanto aos despachos publicados do INPI.

Desta forma, a gestão sobre processos operacionais obedecia ao critério da agilidade no atendimento ao cliente.

Figura 4: Organograma da empresa citada no estudo de caso.

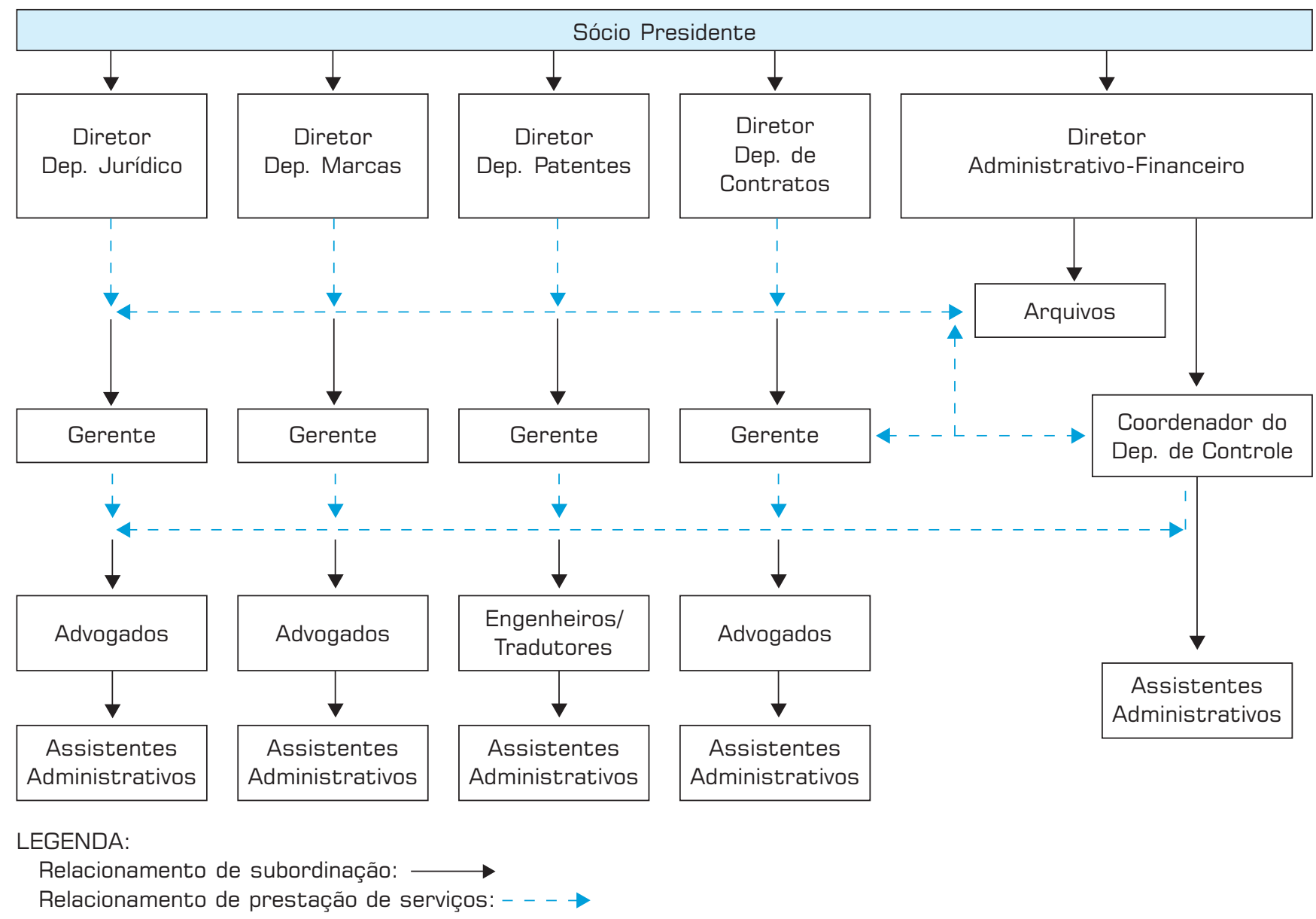


Todo o arcabouço composto pelas operações rotineiras da empresa, seus aperfeiçoamentos e modificações, era construído a partir da observação de erros e acertos ocorridos durante o encaminhamento dos processos e principalmente a partir de reclamações dos clientes. Este item não será aprofundado: sua extensa complexidade para ser descrito constitui-se como irrelevante para o tema deste estudo.

\section{0 foco deste estudo de caso}

$\mathrm{O}$ trabalho presente preocupa-se em descrever o funcionamento do Setor de Controle da referida empresa, por ser o local do acontecimento da experiência com gestão do conhecimento como ferramenta para Qualidade. A Figura 5 esquematiza as rotinas principais deste setor.
O funcionamento do Setor de Controle visava administrar o andamento dos processos sobre marcas e patentes e subseqüentes respostas ao INPI. Também faziam parte das responsabilidades deste setor, receber, classificar e distribuir os projetos dos clientes para os demais setores da empresa, assim como o monitoramento sobre o tempo de atendimento aos clientes. Este setor era formado por 11 pessoas, parte delas com conhecimento razoável de inglês (suficiente para o entendimento e encaminhamento dos pedidos dos clientes) e outra composta por jovens com apenas o segundo grau completo ou nem isto. A rotina de trabalho era de complexidade dinâmica, o que demandava funcionários com segurança no conhecimento não só da LPI mas também da divisão política do escritório e do

Figura 5: Fluxograma demonstrando os movimentos principais do setor em questão

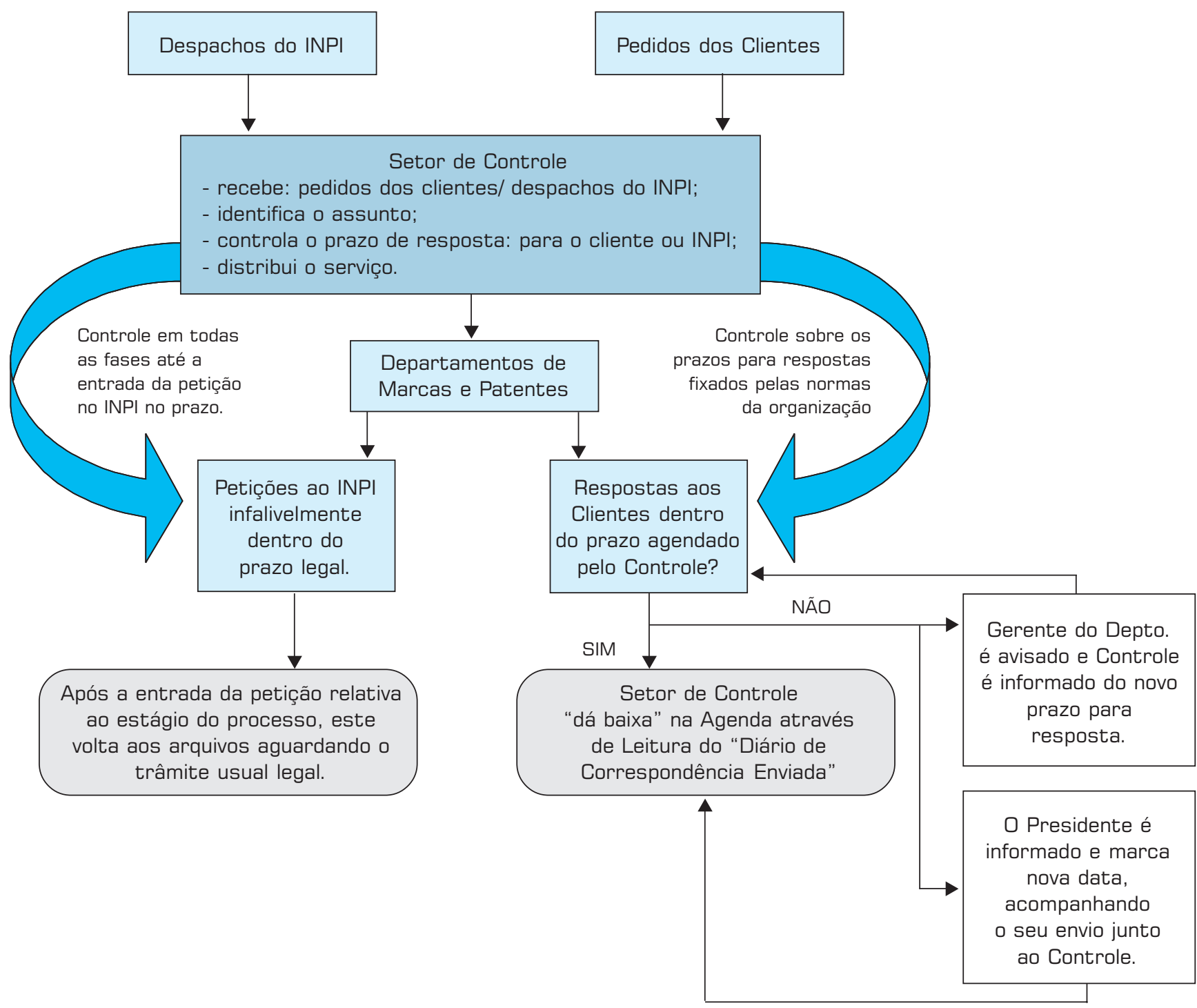


escopo das funções dos demais funcionários, advogados e engenheiros.

\section{Diagnóstico}

A experiência ora analisada teve duração de três anos aproximadamente e foi coordenada por um funcionário experiente, com pleno conhecimento sobre a Lei de Propriedade Industrial, sobre as necessidades dos clientes e sobre a missão e costumes da empresa.

Os autores identificam a transmissão do conhecimento e a gestão por competências como fatores críticos de sucesso para o gerenciamento eficaz do setor de Controle que tinha por responsabilidade monitorar todas as etapas dos projetos dos clientes, apesar de a empresa não disponibilizar os recursos para desenvolvimento das competências dos profissionais:

a) Historicamente, os paralegals para se desenvolverem na empresa citada dependiam da visão dos chefes e coordenadores de setores, sendo os seus treinamentos pouco observados pelos gerentes da área onde se situavam. Os treinamentos eram feitos concomitantemente à entrega de responsabilidades do cargo que os novos funcionários vinham a ocupar, e a aprendizagem contínua e mais aprofundada dependia muito da motivação pessoal do funcionário e de sua habilidade em observar e questionar os dados e informações providas pelos recursos tecnológicos.

b) Em face deste conhecimento administrado com descuido, não existia a mobilidade interdepartamental de funcionários. Vários trabalhadores talentosos permaneceram anos em uma só função, sem que a empresa percebesse que suas habilidades quanto a criatividade e solução de problemas pudessem ser utilizadas para outros fins dentro da organização.

c) Outro problema a ser equacionado pelos responsáveis pelas funções desempenhadas pelos paralegals era que a alta direção da empresa entendia que esta classe de funcionários não necessitava do treinamento especializado ministrado pela já citada associação.

Os riscos de não atendimento às necessidades dos clientes e de ocorrência de falhas graves para a organização, relacionados a sua competência essencial, eram importantes. Uma interpretação errônea sobre um pedido de clientes poderia acarretar a perda irrecorrível de uma marca ou de uma patente. Considerando que marcas e patentes são bens de capital intelectual, qualquer erro grave deste setor poderia trazer complicadas ações judiciais sobre perdas e danos para a organização.

Corroborando para o agravamento da situação já descrita, o sistema informatizado de controles já demonstrava ser notoriamente obsoleto. $\mathrm{O}$ projeto para a modernização e sofisticação do tal sistema estava em andamento, mas, enquanto não se efetivasse, o conhecimento das pessoas teria necessariamente que atuar com segurança.

\section{A identificação da gestão do conhecimento como ferramenta de apoio a obtenção da eficácia \\ "...Quem forma se forma e re-forma ao formar e quem é formado forma-se e forma ao ser formado". \\ Paulo Freire}

Neste ponto do trabalho descreve-se a metodologia que foi identificada e descrita pelo relato que se segue:

a) Foi mapeado o conhecimento de cada funcionário, comparando-o com a necessidade/demanda de conhecimento pelo desempenho da função, com a finalidade de detectar a extensão do treinamento que seria necessário desenvolver.

b) Com os funcionários experientes, que já demonstravam algum domínio sobre Propriedade Industrial, a transmissão de conhecimento acontecia de maneira informal e tempestiva, acompanhando as ações de supervisão de tarefas e tomando como exemplo o estudo dos processos de Marcas e Patentes que estavam sendo cuidados pelo Setor de Controle.

c) No caso dos funcionários recém-admitidos, o treinamento se iniciava naturalmente, a partir da adaptação do funcionário à empresa e sua missão, regras explícitas e tácitas e os clientes internos do Setor de Controle. Simultaneamente, eram transmitidos os conhecimentos básicos sobre a LPI obedecendo de forma didática a uma gradação de dificuldades. As informações sobre as necessidades dos clientes ocorriam durante este momento e pouco a pouco os novos funcionários absorviam as noções fundamentais da Lei e também aumentavam a percepção sobre a missão do próprio setor e da empresa, perante o cliente externo.

\section{Estratégia de utilização da gestão do conhecimento a partir da gestão por competências}

A partir da abordagem adotada e necessitando de apresentar desempenho com qualidade pela equipe sem quebra de ritmo, procurou-se inicialmente desenvolver habilidades no tocante ao recrutamento, selecionando pessoas com predomínio de características/atributos tais como atenção, persistência, seriedade e pró-atividade/ iniciativa, conhecimentos básicos de informática e preferencialmente de inglês. Cabe ressaltar que, quando possível, houve recrutamento interno, com a promoção de pessoas cujas características expressas acima eram notórias e que estavam alocadas em outros departamentos em funções de execução mais simples. Recrutamento interno/externo terminado, passava-se à definição do escopo das atividades individuais. A partir desta metodologia aplicada, era planejado o treinamento de cada um, visando o desempenho correto de suas 
próprias atividades. Posteriormente, era preparado o rodízio, simulando a aplicação do conceito de "células de produção", onde cada funcionário era treinado a desempenhar as funções de seus colegas. A multifuncionalidade obtida facilitava a compreensão da natureza das funções do setor (visão global) assim como facilitava a mobilidade interna em ocasiões de ausências, tais como férias e licenças por motivos de saúde, etc.

Para o treinamento e formação das pessoas, eram utilizados textos e esquematizações gráficas sobre as etapas da LPI e diálogos. Os procedimentos eram transparentes; eventuais erros ou singularidades que ocorressem nos processos eram analisados pela equipe conjuntamente e individualmente, se necessário. Com a utilização de técnicas conhecidas na Gestão da Qualidade Total, tais como brainstorming e GUT, a equipe do Controle conseguia identificar problemas e sugeria soluções que eram implementadas imediatamente. Ao mesmo tempo em que se aprofundava nas questões específicas, avaliava, percebia erros e apontava irregularidades, a equipe amadurecia e solidificava o seu conhecimento geral sobre Propriedade Industrial. Ficou evidente que à medida que adquiria maturidade, a equipe demonstrava coesão, equilíbrio, cooperação e entusiasmo.

Ao longo do tempo, o desempenho diferenciado dos participantes da equipe do Controle foi notado por toda a empresa. Assim que surgiam vagas compatíveis em outros Departamentos, os funcionários do Controle eram lembrados para ocupá-las. Isto resultou em uma nova questão: o Setor de Controle passou a ser um celeiro de talentos.

Funcionários transferidos deste setor para outro que exigisse conhecimento sobre a LPI apresentavam segurança tal que lhes possibilitava encarregarem-se das etapas operacionais das rotinas dos funcionários de postos mais altos. À medida que seus desempenhos poupavam os funcionários de primeiro e segundo escalão das tais tarefas operacionais, a motivação dos jovens transferidos aumentava. Eles percebiam que respondiam com segurança aos desafios das novas atividades e a busca para o conhecimento e melhoria contínua da qualidade de seus serviços passava a ser uma meta pessoal, além de profissional.

\section{Análise dos dados do estudo de caso}

Considerando-se a utilização do raciocínio de um "campo de forças", podem ser identificadas forças restritivas e impulsionadoras quanto ao desempenho do setor e da organização como um todo:

Forças Impulsionadoras:

- Contribuição para o sucesso da organização
Os funcionários transferidos para outros departamentos despontaram em suas carreiras. Com os hábitos e habilidades de trabalho e estudo já formados, foram capazes de enfrentar com brilho os novos desafios. Alguns destes funcionários criaram novos e rentáveis produtos que encontraram exclusividade no mercado.

- Melhoria da qualidade de vida dos funcionários

Todos estes funcionários, jovens provenientes das camadas mais humildes da sociedade, obtiveram, por intermédio deste trabalho, a melhoria de qualidade em sua vida pessoal e profissional. Trabalhadores originalmente condenados a uma vida profissional irregular, para dizer o mínimo, encontraram um espaço para a expansão de seus talentos e adquiriram a capacidade da empregabilidade.

- Desenvolvimento de motivação e comprometimento na equipe

O sucesso nas novas atribuições ampliou a motivação individual e alavancou projetos pessoais de melhoria de vida: todos voltaram a estudar, dirigindo-se para áreas como o Direito ou para outras áreas de conhecimento de alguma forma relacionadas com a empregabilidade em Propriedade Industrial, tais como a Informática ou o estudo de idiomas. Portanto, todos obtiveram uma chance de se enquadrarem no mercado de trabalho e buscavam cada vez mais aperfeiçoarem os seus talentos próprios com o objetivo de aperfeiçoarem também os resultados no trabalho.

\section{comprometimento com a verdade se dá mais facilmente num ambiente onde a visão é compartilhada.}

\section{Forças restritivas}

- O pensamento gerencial da empresa não acompanhou o particular amadurecimento do gestor do Setor de Controle. O reconhecimento da empresa quanto ao aperfeiçoamento contínuo dos funcionários promovidos tampouco se evidenciou de forma expressiva. Nem sempre a transferência para outros departamentos e a entrega a desafios maiores significou um aumento razoável de salário ou a alteração para cargos mais elevados nas carteiras profissionais dos funcionários transferidos. Isto levou estes funcionários a pensarem em buscar novos horizontes profissionais em outros locais. Neste ponto, surge uma questão: a projetada evasão de funcionários bem treinados não se constitui como uma ameaça ao padrão de qualidade da empresa?

Quanto ao Setor de Controle, um problema ficou evidenciado: o progressivo fornecimento de funcionários para outros setores da empresa refletia-se em sua ordem interna 
que se enfraquecia e necessitava ser mantida a todo custo. A alta rotatividade de pessoas ocupando funções estratégicas demandou esforços redobrados por parte de todos os funcionários que permaneceram em seus postos. Para cada funcionário preparado e maduro que fosse transferido para outro departamento da empresa, iniciava-se mais uma vez o procedimento de recrutamento, treinamento e acompanhamento da maturação do novo funcionário até atingir o pleno funcionamento e interagir com a equipe sobrevivente.

A Coordenação do setor procurava habilitar os novos funcionários e aperfeiçoar o conhecimento dos antigos. Entretanto, os esforços para a habilitação de excelência do conhecimento dos funcionários foram desproporcionais ao aumento de volume de trabalho, dado que a empresa observou um crescimento considerável ao longo do tempo que durou esta experiência. Algumas vagas foram abertas no setor de Controle, mas o programa de treinamento ficou bastante prejudicado, pois os funcionários antigos, incluindo os elementos da Coordenação, priorizavam suas rotinas, com o intuito de manter a qualidade da responsividade nos serviços.

Diante da dificuldade em continuar os programas de treinamento, a Coordenação do Setor encaminhou o problema à Alta Direção da empresa, solicitando auxílio para os programas de treinamento. Estes poderiam ser realizados internamente através de profissionais de outros departamentos. A direção da empresa não entendeu assim e não facilitou nenhum programa interno de treinamento. Conseqüentemente, houve perda da qualidade em algumas funções deste setor, já que os novos funcionários não recebiam um treinamento com sofisticação adequada que lhes possibilitasse perceber irregularidades sutis que ocasionalmente surgem neste tipo de serviço.

O caso é concluído com a evasão de vários talentos desta organização.

\section{UMA REFLEXÃO SOBRE OS RESULTADOS}

Com base nos preceitos dos critérios de excelência conforme definidos para o Prêmio Nacional de Qualidade, a análise sobre este episódio aponta as conseqüências da falta de visão e comprometimento da Alta Direção da empresa com o programa de Qualidade Total.

Em primeiro lugar, a empresa não foi capaz de identificar "que a capacitação das pessoas precisa estar alinhada às metas da organização, e que as atividades de educação, treinamento e desenvolvimento das pessoas devem ser permanentes, para que possam se adaptar continuamente às mudanças do ambiente" (FPNQ, 1999). Na verdade, a organização somente valorizava o treinamento das equipes constantes do primeiro e segundo escalões na prestação de serviços (vide organograma na Figura 4), desconhecendo que os processos que suportavam todos os controles e funções da empresa não eram inteligíveis somente a partir do fornecimento dos dados e informações disponíveis através da rede informatizada vigente.

A empresa não deu a devida atenção para a construção global de sua visão sobre a prestação de serviços. Ao deixar de avaliar as reais necessidades operacionais do fluxo de procedimentos que convergiam para o atendimento ao cliente, não enxergou que devia investir sobre a formação profissional adequada para os funcionários de terceiro e quarto escalões. Tais funcionários, quando corretamente capacitados, poupavam os de primeiro e segundo escalões de executarem tarefas enfadonhas e time consuming, além de estarem prontos e vigilantes para quaisquer irregularidades e urgências, que são freqüentes no decorrer dos serviços neste campo.

Em outras palavras, foi percebido que a visão pessoal da Alta Direção da empresa não atrelava a si um comprometimento com a Gestão de Qualidade Total. A organização não percebeu a relação que existia entre a falta de treinamento dos paralegals e a sobrecarga de tarefas deixadas sobre os ombros dos funcionários dos escalões mais altos da empresa, fato que não só deturpava a visão destes sobre a prioridade de rotinas, mas também elevava os custos dos próprios serviços em sua totalidade.

A organização tinha consciência de estar acobertada pela situação singular em que se encontrava: ela situava-se num nicho de mercado onde os concorrentes apresentavam poucas inovações e não demonstravam atenção com programas de melhoria de qualidade.

Em suma, a busca da excelência dos serviços fundamentada no desenvolvimento de talentos não foi reconhecida pela empresa, em primeiro lugar pela falta de alinhamento desta com o conceito de busca de melhoria contínua. E em segundo, pela pouca atenção observada pelos mentores do planejamento estratégico da empresa quanto à gestão de pessoas, que não reparou que a evasão de talentos num negócio onde o conhecimento é ferramenta principal poderia apresentar graves reflexos na qualidade da manutenção dos serviços e conseqüentemente no atendimento aos clientes.

Concluindo, programas de Qualidade Total são muito difíceis de prosperar se experienciados por setores isolados de uma organização. Se não houver uma mudança geral na visão da empresa, a ser compartilhada de cima para baixo, até mesmos os melhores esforços serão malogrados.

\section{SUGESTÕES PARA MUDANC̣AS}

A experiência ora narrada traz a conclusão que, numa proposta para a implantação de conceitos da Qualidade Total em uma empresa semelhante à descrita acima, o planejamento se iniciaria através de mudança de paradig- 
mas. A base da mudança se realizaria através da conscientização, partindo da alta direção até os níveis operacionais mais baixos da empresa, sobre a necessidade de treinar, disseminar o conhecimento e avaliar a sua permanência na empresa para propiciar a melhoria da qualificação organizacional e pessoal.

O presente trabalho privilegia algumas ferramentas estratégicas para o gerenciamento do conhecimento: o fortalecimento de lideranças, a identificação dos processos da gestão do conhecimento e a mudança do sistema de méritos e recompensas.

\section{0 conhecimento como instrumento para implantação da gestão de qualidade total nas empresas.}

E observado que a implantação de programas de qualidade total nas empresas deve ser permeado do compartilhamento da visão genérica deste conceito, além de abordar áreas críticas do conhecimento organizacional como:

- Preferências e necessidades dos clientes;

- Conhecimento da concorrência;

- Aplicações da tecnologia;

- Mapeamento e uso da informação existente;

- Mapeamento de setores e nichos de mercado;

- Regulamentações externas e internas.

Para um esboço de método para a gestão do conhecimento organizacional, cabe citar Quinn (1998), que divide em quatro níveis o funcionamento do intelecto profissional de uma organização, que estão apresentados em ordem crescente de importância:

Conhecimento cognitivo (ou KNOW-WHAT): é o domínio básico de uma disciplina que os profissionais atingem através de extenso treinamento e certificação. Esse conhecimento é essencial, mas longe de suficiente, para o sucesso comercial;

Habilidades avançadas (ou KNOW-HOW): traduzem a "aprendizagem nos livros" em execução eficaz. A capacidade de aplicar as regras de uma disciplina a problemas complexos do mundo real é o nível de habilidade profissional que mais cria valor.

Compreensão de sistemas (ou KNOW-WHY): é um profundo conhecimento da teia de relacionamentos causa e efeito básicos de uma disciplina. Permite aos profissionais irem além da execução de tarefas para resolver problemas maiores e mais complexos - e criarem valor extraordinário.

Criatividade automotivada (CARE-WHY): consiste da vontade, da motivação e da adaptabilidade para o sucesso. Grupos altamente motivados e criativos frequientemente têm melhor desempenho do que outros grupos com maiores recursos físicos ou financeiros.
Mas como criar condições e apoiar o desenvolvimento e a comunicação deste conhecimento; ou seja, como transformar conhecimento em ativo a serviço da organização ao invés de apenas propriedade de indivíduos ou grupos internos?

Segundo Senge (1998) "as organizações só aprendem por meio de indivíduos que aprendem. A aprendizagem individual não garante a aprendizagem organizacional. Entretanto, sem ela, a aprendizagem organizacional não ocorre".

Conforme examinado anteriormente, uma empresa que possua um enfoque atualizado em Gestão de Pessoas poderá propiciar um ambiente organizacional que possibilite aos funcionários desenvolverem o que Senge (1998) denomina "domínio pessoal", "comprometimento com a verdade" e "visão compartilhada".

O domínio pessoal é formado primeiramente do contínuo esclarecimento, ou seja, da visão sobre o que se quer; e em segundo lugar de aprender continuamente a ver a realidade: onde se está em relação ao que se quer. Senge (1998) cita Kazuo Inamori, da Kyocera, que "estimula os funcionários a olhar para dentro de si mesmos".

\section{compartilhamento da visão é \\ uma das principais condições} para a gestão do conhecimento.

Destacar a importância do comprometimento com a verdade atinge níveis bem mais profundos do que o das relações interpessoais num ambiente organizacional. O trabalhador que relata o seu desconhecimento sobre alguma prática está sinalizando o seu desejo em aprendê-la. Assim, demonstra a confiança de quem espera ser atendido em sua demanda. Se o comprometimento com a verdade tiver ressonância se não em toda organização mas dentro de células da organização, pode-se almejar um clima propício para a investigação dos eventos e a identificação das causas dos limitadores de crescimento.

O comprometimento com a verdade se dá mais facilmente num ambiente onde a visão é compartilhada. Senge (1998) afirma: "Não existe organização que aprende se não houver visão compartilhada". A criação de visão é dada pelos líderes com sensibilidade para reconhecer talentos e trabalhar oportunidades com a comunicação da visão. $\mathrm{O}$ compartilhamento da visão é uma das principais condições para a gestão do conhecimento. É o terreno onde a aprendizagem germina e frutifica. Se existe um trabalho contínuo investigador e esclarecedor sobre as metas da empresa, que por sua vez podem acomodar as metas pessoais, vai se 
instalar o compartilhamento da visão. Novamente citando Senge (1998), “a visão compartilhada, principalmente a intrínseca conduz as aspirações das pessoas. O trabalho torna-se parte da busca de um propósito superior incorporado aos produtos e serviços das organizações".

Os autores entendem que a gestão do conhecimento numa empresa poderá prosperar se favorecida por um clima organizacional de cooperação e de confiança onde possa frutificar o empenho dos indivíduos a desenvolverem suas visões pessoais de acordo com as da empresa. Ou seja, fortalecer a idéia de que o desenvolvimento pessoal é valorizado pela empresa. Deste ponto surgem importantes caminhos: o que aponta para uma liderança sensível e cuidadosa, a atenção sustentada pelo planejamento da empresa sobre a elaboração formal de processo de adaptação, criação, captura e utilização do conhecimento e finalmente outro, o que determina uma revisão no sistema de méritos e recompensas utilizado pela empresa.

\section{Liderança: Ferramenta Estratégica para a Gestão do Conhecimento}

Comecemos pela liderança. Fortalecer a liderança é uma das estratégias mais importantes para a gestão do conhecimento. Segundo Stewart (2001), nos últimos três anos do século XX, o título "principal executivo do conhecimento" (chief knowledge officer - CKO) difundiu-se com muita rapidez. John Peetz, que exercia esta função na Ernest \& Young, identificou as três principais responsabilidades de um CKO: catequizar quanto ao valor do compartilhamento do conhecimento; apoiar e operar projetos que descubram, divulguem e distribuam o conhecimento em toda a empresa. (STEWART, 2001).

Davenport \& Prusak (1998), em comentários a respeito dos diretores do conhecimento ou CKO, afirmam:

"Embora os especialistas sejam fundamentais para o sucesso da gestão do conhecimento, ainda mais importantes são as atividades e atitudes daqueles que são pagos para desempenhar outras tarefas que não a de gerir o conhecimento. Gerentes de planejamento, analistas de negócios, engenheiros de projeto e produção, profissionais de marketing e até mesmo secretárias e pessoal de suporte administrativo são os mais importantes gerentes do conhecimento. Todos eles precisam criar, compartilhar, pesquisar e usar o conhecimento em sua rotina diária. Neste sentido, a gestão do conhecimento deve ser parte do trabalho de cada um dos membros da empresa".

Os autores do presente trabalho privilegiam a função dos gerentes e outros cargos em funções de liderança, como peças fundamentais no desenvolvimento da gestão do conhecimento.

Nos programas de Qualidade Total, a meta é haver equipes se comunicando de forma aberta, e o binômio treinamento/produção é auto-estimulante. Entretanto, o fortalecimento das equipes pode se tornar perigoso para a estrutura de poder vigente na empresa; vide comentários de Fleury e Fleury (1995) apud Oliveira Júnior (2001). Senge (1998) comenta que as relações hierárquicas ficam ameaçadas e cresce um conceito subliminar de que a melhoria contínua vis-à-vis a redução de custo fomentada pelos funcionários chega a incomodar de tal forma a camada gerencial, que freqüentemente opta por demitir as lideranças. Neste cenário, gerentes lidam com a melhoria trazida pelos funcionários com polida indiferença, por não estarem preparados para assistir ao desenvolvimento de lideranças altamente produtivas e criativas debaixo dos seus narizes. Como resultado, as medidas sugeridas pelos trabalhadores não são implementadas. O trabalho do círculo de qualidade estagna para depois declinar. Jack Welch, o legendário CEO da General Electric, certa vez declarou: "Weak managers are the killers of business; they are job killers". (Heskett, 2000).

\section{Processo para a Gestão do Conhecimento Organizacional}

O processo da Gestão do Conhecimento tem fases bem definidas, desde a criação do conhecimento até a sua utilização para criar valor para a empresa. A Figura 6, adaptada a

Figura 6: Fases da Gestão do Conhecimento.

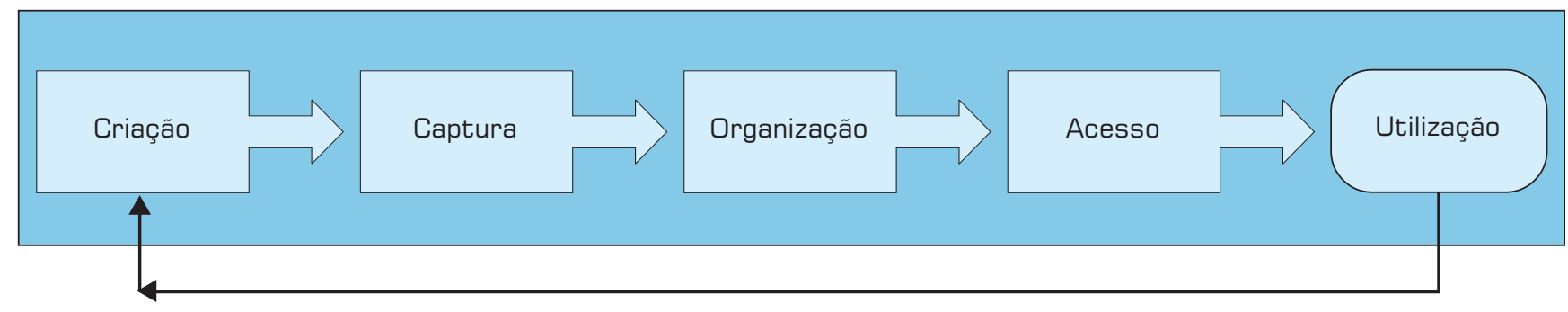

Fonte: Adaptado de Harris et al. (ap. Korowasjczuk, 2000) 
partir de Korowasjczuk et al. (2000) representa de forma objetiva estas fases.

O conhecimento pode ser gerado, desenvolvido e compartilhado dentro das fronteiras de uma organização. Kathy Harris et al. apud Korowasjczuk (2000) identifica uma metodologia do Processo de Gestão de Conhecimento conforme concisamente demonstrado na Tabela 1.

A natureza dinâmica das etapas deste processo exige que as lideranças formais e informais se encarreguem de agir como condutores para que estas etapas não deixem de ser identificadas nas rotinas, cumprimento de prazos e necessidades básicas administrativas de uma empresa.

\section{Revisando o sistema de méritos e recompensas.}

O outro caminho para fortalecimento do clima organizacional favorável ao conhecimento leva à análise do sistema de méritos e recompensas da empresa. Ora, considerando que conhecimento é o ativo intangível de uma organização, como transformá-lo num bem comum, criando possibilidades de usá-lo como ferramenta para alavancar a empresa para um estado de alta competitividade no mercado? Estimulando-o.
É curioso observar que a produção de conhecimento se dá em grande escala por vias informais, principalmente quando se focalizam empresas de prestação de serviços (vide comentário à pág. 18, extraído de DAVENPORT \& PRUSAK, 1998). Empresários devem lembrar-se que sistemas tecnológicos podem ajudar mas, por si só, não criam o ambiente onde as pessoas - que são as que detém o conhecimento - contatem e comuniquem, de uma forma eficaz e empenhada, entre si. O saber coletivo só pode nascer da vontade de partilhar.

A sugestão para a abordagem sobre os méritos e recompensas pessoais não aponta para nenhum procedimento que possa causar dano às relações de custo/benefício inerentes aos compromissos trabalhistas de uma organização. Existem várias medidas que podem ser tomadas pela empresa que podem ratificar sua aprovação sobre a transmissão do conhecimento perante seus funcionários. Uma menção elogiosa no quadro mural da empresa, por exemplo, é medida eficaz e duradoura para o funcionário que a recebe, porque fomenta o seu prestígio perante os colegas e vai gradualmente estimulá-los a imitarem as suas atitudes.

Tabela 1: Tabela de detalhamento das fases do Processo da Gestão do Conhecimento.

\begin{tabular}{|c|c|c|}
\hline $\begin{array}{l}\text { ETAPAS DO PROCESSO DE } \\
\text { GESTÃO DO CONHECIMENTO }\end{array}$ & DETALHAMENTO & $\begin{array}{c}\text { AÇÕES } \\
\text { COMPREENDIDAS }\end{array}$ \\
\hline Criação & $\begin{array}{l}\text { Resulta em novo conhecimento ou nova } \\
\text { apresentação do conhecimento já existente }\end{array}$ & $\begin{array}{l}\text { Descobrir } \\
\text { Realizar } \\
\text { Articular } \\
\text { Discutir }\end{array}$ \\
\hline Captura & $\begin{array}{l}\text { Requer a articulação de conceitos e } \\
\text { discernimento para a captura de } \\
\text { conhecimento informal na forma explícita, } \\
\text { conversão de informação de uma mídia para } \\
\text { outra. }\end{array}$ & $\begin{array}{l}\text { Digitalizar } \\
\text { Documentar } \\
\text { Extrair } \\
\text { Representar } \\
\text { Armazenar }\end{array}$ \\
\hline Organização & $\begin{array}{l}\text { Inclui as atividades que classificam e } \\
\text { categorizam o conhecimento para navegação, } \\
\text { armazenagem e recuperação. }\end{array}$ & $\begin{array}{l}\text { Estruturar } \\
\text { Catalogar } \\
\text { Abstrair } \\
\text { Analisar } \\
\text { Categorizar }\end{array}$ \\
\hline Acesso & $\begin{array}{l}\text { Fornecimento ou disseminação de } \\
\text { conhecimento, diretamente ou atendendo a } \\
\text { um programa de perfil do usuário. }\end{array}$ & $\begin{array}{l}\text { Apresentar } \\
\text { Mostrar } \\
\text { Notificar } \\
\text { Achar } \\
\text { Perfilar }\end{array}$ \\
\hline Utilização & $\begin{array}{l}\text { Permite que seja feito uso efetivo do } \\
\text { conhecimento necessário para a atividade de } \\
\text { negócio. }\end{array}$ & $\begin{array}{l}\text { Fazer } \\
\text { Servir } \\
\text { Aprender } \\
\text { Desenvolver } \\
\text { Desempenhar }\end{array}$ \\
\hline
\end{tabular}

Fonte: Adaptado de Kathy Harris et al. (ap. Korowasjczuk, 2000) 


\section{CONCLUSÃO}

Este estudo procurou destacar a importância da gestão do conhecimento como um fator fundamental para a Qualidade Total no desempenho final das organizações. Em empresas de prestação de serviços, este fator tem sua importância redobrada, por estar o seu funcionamento intimamente conectado ao conhecimento vivo das pessoas.

Outra conclusão que se segue a este estudo, é a inegável contribuição que o conhecimento desenvolvido na empresa traz para as vidas humanas que a compõem. A empresa tem um papel social na vida de seus trabalhadores à medida que os favorece com um aprendizado que garante a empregabilidade até para aqueles que ainda não haviam sido favorecidos pelo sistema formal de educação no país.

Ao gerir com sucesso a transmissão e permanência do conhecimento em seus domínios, a empresa fortalece o seu clima organizacional tornando-o capaz de abrigar mentes criativas e cooperadoras e fortalece as relações humanas num campo fértil de curiosidade e generosidade.

\section{Edicão especial início $07 / 03 / 2003$ fim $25 / 08 / 2003$}

\section{- Bibliografia}

CAMPOS, Vicente Falconi. O Valor dos Recursos Humanos na Era do Conhecimento. 6. ed., Belo Horizonte : MG, Ed. Do Desenvolvimento Gerencial, 1995.

DAVENPORT, Thomas, PRUSAK, Lawrence. Conhecimento Empresarial. São Paulo : Publifolha e Ed. Campus Ltda., 1999.

DEL PINO, Mauro Augusto Burkert. Educação, Trabalho e Novas Tecnologias. Pelotas, RS : Ed. Universitária/UFPel; 1997.

DRUCKER, Peter. Sociedade PósCapitalista. São Paulo : Publifolha e Enio Guazelli \& Cia.,1999.

EDVINSSON, Leif, MALONE, Michael S. Capital Intelectual. São Paulo : Makron Books, 1998.
FUNDAÇÃO Getúlio Vargas - CADEMP. Anotações em curso de Administração em Recursos Humanos. Recrutamento e Seleção - 2001. RJ.

FUNDAÇÃO para o Prêmio Nacional da Qualidade. Critérios de Excelência para o Prêmio Nacional da Qualidade. PNQ 1999 - São Paulo, Fundação para o Prêmio Nacional da Qualidade, 1999.

HESKETT, James L. GE... We bring good things to life. Harvard Business Review, fev. 2000 .

KLEIN, David A. A Gestão Estratégica do Capital Intelectual. Rio de Janeiro : Qualitymark Ed., 1998.

KOROWAJCZUK, Alexandre, CASATILHO, Bernadette S.C., COSSICH, Edson José, FRÓES, Fábio José C.S., FERRÃO, Gilberto da Silva. Avaliação de Organizações em relação à Gestão do Conhecimento com base nos Critérios de Excelência da Fundação para o Prêmio Nacional da Qualidade Monografia do Curso de Pós-Graduação em Gestão Estratégica do Conhecimento e Inteligência Empresarial da PUC do Paraná, fevereiro 2000.

MAMANI, Alberto Gonzales. Gestão Estratégica de Pessoas: Proposta com Foco em Gestão por Competências. Estudo de Empresas da Construcão Civil-Dissertação apresentada ao Curso de Pós-Graduação em Engenharia Civil da Universidade Federal Fluminense, como requisito parcial para obtenção do Grau de Mestre em Engenharia.RJ, 2002. Orientador: Osvaldo Quelhas.

OLIVEIRA JÚNIOR, M.M Competitividade Baseada no Conhecimento, in CAVALCANTI, M. Gestão Estratégica de Negócios evolução, cenários, diagnóstico e ação. São Paulo Ed. Pioneira Thomson Learning, 2001.
QUINN, James Brian, ANDERSON, Philip e FINKELSTEIN, Sydney. Gerenciando o Intelecto Profissional: Obtendo o Máximo do Melhor. In A Gestão Estratégica do Capital Intelectual, São Paulo : Quality Mark,1998. Reproduzido com permissão da Harvard Business Review de "Managing Professional Intellectual: Making Most of the Best", de James Brian Quinn et al., março-abril 1996, pp 71-80.

SENGE, Peter - A Quinta Disciplina - $3^{\text {a }}$ Edição, São Paulo, Ed. Best Seller, 1998.

SENGE, Peter. A Dança das Mudanças. 3. ed. Rio de Janeiro : Ed. Campus, 1999.

STEWART, Thomas. A Riqueza do Conhecimento, Rio de Janeiro : Ed. Campus, 2002. 